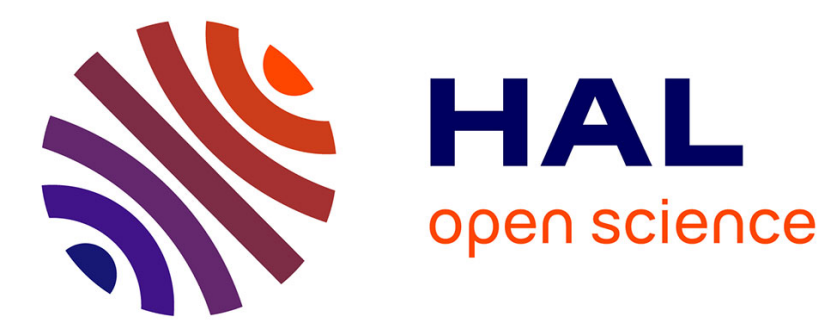

\title{
Content, mode, and self-reference
}

François Recanati

\section{To cite this version:}

François Recanati. Content, mode, and self-reference. S. Tsohatzidis. John Searle's Philosophy of Language: Force, Meaning, and Thought., Cambridge University Press, 2006. ijn_00089222

\section{HAL Id: ijn_00089222 \\ https://hal.science/ijn_00089222}

Submitted on 13 Aug 2006

HAL is a multi-disciplinary open access archive for the deposit and dissemination of scientific research documents, whether they are published or not. The documents may come from teaching and research institutions in France or abroad, or from public or private research centers.
L'archive ouverte pluridisciplinaire HAL, est destinée au dépôt et à la diffusion de documents scientifiques de niveau recherche, publiés ou non, émanant des établissements d'enseignement et de recherche français ou étrangers, des laboratoires publics ou privés. 


\title{
Content, mode, and self-reference
}

\author{
François Recanati \\ Institut Jean-Nicod, Paris \\ recanati@ens.fr
}

To appear in S. Tsohatzidis (ed.)

John Searle's Philosophy of Language :

Force, Meaning, and Thought.

Cambridge : Cambridge University Press.

1. Illocutionary force, psychological mode, and the fallacy of misplaced information

Searle famously characterized speech act types in terms of a number of 'conditions' or 'rules' they are supposed to obey, including conditions on their propositional content. If I order John to wash the dishes, the content of the order is the proposition that John will wash the dishes - the same proposition that would be the content of an assertion if I said that John will wash the dishes, or of a question if I asked whether John will wash the dishes. While assertions or questions can have any proposition as their contents, however, orders and directive speech acts more generally are supposed to be more constrained : their content can only be a proposition bearing upon a future act of the hearer, as in this particular case. Likewise, promises are such that their contents can only be a future act of the speaker (Searle 1969 : 57-58).

In my own book on speech acts I criticized Searle's claim and argued that it rests on what Barwise and Perry later dubbed the 'fallacy of misplaced information'1 :

The notion of the hearer's (or speaker's) future behavior does have a role to play in the analysis of commissives and directives, but... the proper place for this notion is in the analysis of the illocutionary force of directives and commissives, not in the analysis of their propositional content. Any proposition whatever can be the content of a directive or a commissive ; it suffices that the

\footnotetext{
${ }^{1}$ See Barwise and Perry $1983: 38,164$, etc.
} 
speaker's utterance express his intention that the hearer (or the speaker), by virtue of this utterance expressing this intention, behave in such a way as to make the proposition true. The 'hearer's (or speaker's) future behavior' consists in bringing about the state of affairs that is the content of the speech act. It is not an intrinsic aspect of that state of affairs. (Recanati $1987: 163$, originally in Recanati 1981: 189 ; see also Sperber $1982: 47$ )

As I pointed out in the same book, Searle's view has unfortunate consequences : it forces the theorist to treat as indirect the illocutionary act of promise performed by means of a sentence such as 'You will win' (said by a tennis player to his opponent), while the same act would be performed directly if the speaker had uttered 'I will lose' instead. This sounds arbitrary. Again, any future state of affairs can be the content of an order (or a promise) if the utterance manifests the speaker's intention that, because of this utterance, the addressee (or the speaker) will bring about that state of affairs. Even the futurity of the state of affairs is not a genuine constraint on the propositional content of commissives or directives. To be sure, it is a natural constraint that humans can only actualize the future, since the past is beyond their control ; but that is not a conventional, linguistic constraint.

In his later work, Searle emphasized the similarity between speech acts and mental states. Both have a propositional content, and both have a dual structure, with the 'psychological mode' corresponding, on the side of mental states, to the illocutionary force on the side of speech acts. To assert that $p$ is to perform a speech act whose content is the proposition that $p$ and whose force is that of an assertion. Likewise, to believe that $p$ is to be in an intentional state whose content is the proposition that $p$ and whose psychological mode is that of belief. Now, because of that dual aspect, it is all too easy to 'misplace' some of the information carried by a mental state, by ascribing to the content of the state a piece of information that is actually carried by its mode - just as Searle misleadingly ascribed to the propositional content of directive and commissive speech acts what was actually a feature of their illocutionary force.

Indeed, I think Searle himself has been guilty of such misplacement in his insightful analysis of perceptual experiences (a sub-class of Intentional states). Besides making the distinction I have just introduced, between the content of the state and its mode, Searle distinguishes two conditions such that the experience 
counts as satisfied (veridical) if and only if they are both met : the primary condition and the self-referential condition. (Those are my terms, not Searle's.) For Searle, both the primary condition and the self-referential condition are determined by the propositional content of the experience ; he therefore construes that propositional content as self-referential. If I am right, however, the propositional content of the experience only determines the first component of its overall truth-conditions - what I called the primary condition. The self-referential condition is not determined by the propositional content of the state, but by its mode. It follows that the propositional content of a perceptual state is not self-referential, even if its overall truth-conditions are.

\section{The content of perceptual experience : Searle's analysis}

Visual experiences have propositional content, Searle claims. The subject does not merely see a flower, he sees a flower there, and this, fully spelled out, means that he sees that there is a flower there. I understand Searle's contention as follows : the subject, as part of his visual experience, makes certain perceptual judgments, which determine the (conceptual) content of the experience. So the propositional content of the experience is the content of the judgments that are immediately (i.e. noninferentially) based on it. ${ }^{2}$

Let us ask what the truth-conditions of the perceptual judgement are. For the perceptual experience to be veridical, Searle says, there must actually be a flower there, but that is not sufficient. In addition to the primary condition that there be a flower there, an extra condition must be met : it must be the case that the presence of a flower there causes the visual experience (including the judgment that is part and parcel of the experience). Insofar as the propositional content of the state is what determines its truth-conditions, the content of the visual experience turns out to be more complex than one might have thought. The content of the visual experience is not the simple proposition that there is a flower there, but the conjunctive proposition that there is a flower there and there being a flower there causes this visual experience (where 'this visual experience' reflexively refers to the experience of

\footnotetext{
2 I know this is not how Searle himself puts the matter, but the difference in formulation is not important in the context of the present discussion.
} 
which this is the propositional content). Searle therefore provides the following analysis of the perceptual experience of seeing a flower there. As in speech act theory, the stuff in capital letters indicates the mode, while the materials within the parentheses specify the content.

VIS EXP (that there is a flower there and that there is a flower there is causing this visual experience)

According to this analysis, the intentional state is a visual experience (mode) and its content is a conjunctive proposition whose second conjunct refers to the very experience of which this is the content, while the first conjunct specifies 'the state of affairs perceived' (Searle $1983: 48$; I suppose this means something like : the state of affairs which the speaker takes himself to be perceiving). The first conjunct determines a proper part of the judgment's truth-conditions, namely the primary condition : that there be a flower there. But there is another truth-condition, determined by the second conjunct. That is the self-referential condition : that the perceptual experience be caused by 'the rest of its truth-conditions', that is, by the state of affairs whose existence is the primary condition. Because of the second condition, the overall truth-conditions of the perceptual judgment are self-referential : for the perceptual judgment to be veridical, the state of affairs which the speaker takes himself to be perceiving must actually exist (primary condition), and it must be what causes the speaker's perceptual judgement that that state of affairs exists (selfreferential condition).

\section{What is wrong with Searle's analysis}

I agree with Searle that there are these two components in the truth-conditions of perceptual judgements. But I deplore Searle's claim that the overall truth-conditional content of the judgment, with its two components, is the propositional content of the visual experience (as distinguished from its mode). Insofar as I can tell, this is the fallacy of misplaced information once again.

That the state of affairs represented (there being a flower there) causes the representation of that state of affairs is a condition that has to be met for the representation in question to count as a perception (rather than, say, an expectation). 
It follows that the self-referential condition is determined by the perceptual mode of the state, not by its content. ${ }^{3}$ For a representation that $p$ to count as a perception that $p$, it must be the case that the representation is caused by the fact that $p$; but what is represented is only the fact that $p$. In other words : the content of the state (viz. the proposition that $p$ ) only determines the primary condition ; the perceptual nature of the state is what determines the self-referential condition. Together, the content and the mode determine the overall truth-conditions of the state.

Searle might insist that, for him, the propositional content of a state just is what determines its truth-conditions. Consider the following passage, where he introduces the idea of propositional content :

Every Intentional state consists of an Intentional content in a psychological mode. Where that content is a whole proposition and where there is a direction of fit, the Intentional content determines the conditions of satisfaction. Conditions of satisfaction are those conditions which, as determined by the Intentional content, must obtain if the state is to be satisfied. For this reason the specification of the content already is a specification of the conditions of satisfaction. Thus, if I have a belief that it is raining, the content of my belief is : that it is raining. And the conditions of satisfaction are : that it is raining. (Searle $1983: 12-13$ )

Given this characterization of content, it is legitimate to use the overall truthconditions of perceptual experiences as evidence to determine what their content is. Following this procedure, we end up with Searle's conclusion : the propositional content of a visual experience is self-referential.

But I do not think we can accept this defense. Searle cannot simply 'define' the propositional content of a state as that which determines its truth-conditions. Or rather, he can, but then the claim that the content so defined is (to some extent) independent of the mode becomes an empirical claim, and it is that claim which I

\footnotetext{
${ }^{3}$ Thus I concur with Kent Bach who writes, in his contribution to this volume : « It is not the content of a visual experience that determines that its cause is its object. Rather, it is the psychological mode. It is the fact that the experience is perceptual that determines that its $\operatorname{object}(\mathrm{s})$ is that which causes, in the appropriate way, that very state. »
} 
reject. ${ }^{4}$ There is a sense of 'content' in which the content of perceptual judgments is self-referential ; but the 'content', in that sense, is determined in part by the mode, and in part by... the content of the state in a different sense, namely, the sense in which 'content' and 'mode' are two independent dimensions which together constitute the state. My point, therefore, is that Searle cannot simultaneously maintain that the content is what determines the conditions of satisfaction, and that the content is independent from the mode. There are two distinct notions of content : one that is involved in the mode/content distinction inspired from speech act theory, and another one that is involved in the claim that the content of a state is what determines its (overall) truth-conditions.

A second line of response is available to Searle. He may insist that it is part of the subject's perceptual experience that that experience is caused by its object. The 'causation' component is not external to the content of the experience, but an integral part of it. With this I agree - but I do not think Searle's position is thereby justified. The subject is aware of the perceptual nature of his experience : he knows he is perceiving rather than, say, expecting or imagining. So there is a sense in which the complete content of his experience is self-referential : but the 'complete content' of the experience involves more than the propositional content - it also involves the psychological mode, of which the subject is aware and which determines the additional, self-referential condition.

Once again, the analogy with speech acts can be illuminating. There is a selfreferential element in speech acts too, as several authors have pointed out. For

\footnotetext{
${ }^{4}$ In response, Searle might point out that he never claimed that the content was independent of the other component (mode or force) : the very idea of a 'propositional content condition' argues against such independence. This point is well-taken, but I reply that the distinction between 'content' and 'mode' (or 'force'), by itself, implies that these are relatively independent dimensions. However lightly we construe this 'independence' condition, it will not be satisfied (I claim) if we follow Searle and define content as that which determines satisfaction conditions. Searle himself concurrently uses a distinct notion of content, namely (for any type of speech act or Intentional state $F$ ) what the subject $F \mathrm{~s}$ : what she believes, what she asserts, what she promises, what she perceives, etc. The content of the act/state, in this sense, satisfies the independence condition, and it is not self-referential (as Searle himself admits).
} 
example, an order represents a certain state of affairs as a state of affairs such that the addressee complies with the order only if he brings it about. But bringing about the state of affairs in question is not sufficient for compliance : it must be the case that the addressee brings about the state of affairs as a result of being ordered to do so. An order, therefore, presents a state of affairs as something which the hearer is to bring about as a result of this order. So there are two components in the obedience conditions of an order : the hearer must do something (primary condition), and the order must be what causes the hearer to do that thing (self-referential condition). But it would be a mistake to consider the second, self-referential condition (that the order be what causes the hearer to do $x$ ) as determined by the content of the order (i.e. what is ordered), as opposed to its force. The speaker orders the hearer to do $x$, period; he does not order her to do $x$ because of this order. Yet the fact that the utterance is an order (rather than an assertion) means that the hearer's doing $x$ will count as satisfying the speech act only if the hearer's doing $x$ is caused by the speech act in the proper way. This is a feature of the illocutionary force of ordering. So the correct representation of the speech act of, say, ordering the hearer to wash the dishes is not

ORDER (that the addressee washes the dishes and that the addressee washes the dishes is caused by this order)

but simply

ORDER (that the addressee washes the dishes) ${ }^{5}$

I think exactly the same considerations apply in the perception case. The proper representation of the perceptual experience of the subject who sees a flower there is not

\footnotetext{
${ }^{5}$ As Savas Tsohatzidis pointed out to me, the analysis of directives I am criticizing here as incorrect (that which construes their content as self-referential) is explicitly endorsed by Searle in Intentionality (Searle 1983: 86).
} 
VIS EXP (that there is a flower there and that there is a flower there is causing this visual experience)

but simply

VIS EXP (that there is a flower there)

In other words, the content of the perception of a flower is the fact that there is a flower there. That fact can be represented in all sorts of modes ; for it to be represented in the perceptual mode, it must be the case that the fact itself causes the representation. But this feature, hence the self-referential component whose importance Searle rightly emphasizes, is a property of the perceptual mode of representation, not a property of the content of perceptual representations. Or rather : it is a property of their content, but not in the sense in which 'content' contrasts with 'mode'. We should distinguish the narrow content of an Intentional state (or, for that matter, of a speech act) and its 'overall' or 'complete' content which includes the aspects of content determined by the mode.

\section{Reflexive truth-conditions without reflexive content}

The distinction between the two levels of content is the core of a view I have been trying to develop over the years, within a situation-theoretic framework (Recanati 1996, 1997, 1999, 2000, forthcoming). The basic idea is this : when we think or talk, the content of what we think or say is to be evaluated with respect to some situation (or class of situations), and the truth-value of what we say or think depends both upon the content of what we say and think and upon the situation with respect to which it is supposed to be evaluated. Not only the truth-value : as we shall see, the truth-conditions of the utterance/thought crucially depend upon the situation, and they correspond to the second level of content : the 'complete' or 'overall' content of the utterance/thought.

In the language case, the situation is often a matter of speaker's intentions : the situation is tacitly referred to by the speaker. For example, imagine the speaker and his addressee are watching four people playing a poker game, and the speaker says : 'Claire has a good hand!'. This is true if and only if Claire has a good hand in 
the poker game they are watching. The situation tacitly referred to by the speaker finds its way into the truth-conditions of the utterance even though nothing in the sentence stands for that situation. The sentence expresses the proposition that Claire has a good hand, a proposition that would be true if Claire was playing bridge at the other end of town and had a good hand there ; but the (complete) content of the utterance is richer than that. It involves that proposition plus the situation the speaker tacitly refers to, and it is true iff the proposition in question is true in the situation in question.

While, in speech, the situation with respect to which the utterance is meant to be evaluated is tactily referred to, in thought it is often determined by the architecture of the system. Thus a perception is bound to be evaluated in the situation that causally affects the subject's senses and is responsible for the perception. In Searle's flower example, the content of the perception, in the narrow sense, is simply the fact that there is a flower ; but for the perception to be veridical, that fact must obtain in the situation that the subject sees, i.e. that which causes his or her visual experience. On this view the self-referential condition is a crucial aspect of the perception's truthconditions, as Searle claims, but it is captured within the 'situational' component of the overall content.

We can extend this analysis to the whole class of Intentional states which involve a self-referential component - the 'reflexive states', as Higginbotham (2003) calls them. In what follows I will discuss two examples for which Higginbotham provides detailed self-referential analyses in the spirit of Searle's analysis of perceptual experience.

The first example is episodic memory. For the subject's memory that $p$ to be veridical, Searle points out, it must have been the case that $p$, but that is not sufficient : the fact that $p$ must have caused a perception that left the memory as a trace. ${ }^{6}$ In stating the memory's truth-conditions we cannot avoid referring to the memory state itself. According to Higginbotham, the subject who remembers having

\footnotetext{
6 « The memory of seeing the flower represents both the visual experience and the flower and is self-referential in the sense that, unless the memory was caused by the visual experience which in turn was caused by the presence of (and features of) the flower, I didn't really remember seeing the flower. » (Searle $1983: 95)$
} 
been elected entertains a memory $e_{1}$ the content of which is the following proposition :

(1) $\quad\left(\exists e_{2}\right)$ Is-elected $\left(\sigma\left(e_{1}\right), e_{2}\right) \& e_{2}<e_{1}$

That is the proposition that there is an event of being elected whose subject is the subject of this memory state and whose time is anterior to the time of this memory state. The proposition in question is doubly reflexive : it refers to the subject who undergoes the memory state of which it is the content, and it locates the event $e_{2}$ as anterior to that memory state (' $<$ ' is the relation of temporal precedence). Searle would presumably add a further component, pertaining to the causal relation between the event $e_{2}$ and the memory state $e_{1}$.

In contrast to Searle and Higginbotham, I take the content of the subject's memory in Higginbotham's example to be simply the event of being elected. In the Davidsonian framework favoured by Higginbotham, this simple content can be represented as (2) :

(2) ( $\quad \exists e)$ Is-elected $(x, e)$

One nice consequence of the view that the overall content of a representation divides into the content proper and a situational component is that the content proper can be made very simple, so simple that in many cases it will be less than fully propositional (in the classical sense of 'proposition'). Here (2) is not a complete proposition, by Fregean standards ; it is only a propositional function. Or, if it is to count as a proposition, it will be in the sense in which Prior's tense logic posits 'propositions' that are true with respect to times (Prior 1967, 1968), and Prior's egocentric logic 'propositions' that are true with respect to persons (Prior 1977). Indeed (2) is the 'proposition' that one is elected - a proposition which (given a fixed world) is true at all and only those person-time pairs $\langle x, t\rangle$ such that $x$ is elected at $t$. In contrast to classical propositions, which are true or false tout court, such a 'relativized' proposition is only true (or false) with respect to individual-time pairs.

For a memory with that proposition as content to be true tout court, the proposition in question must be true with respect to the subject who remembers and 
a time anterior to the memory. ${ }^{7}$ It follows that if John has, at time $t^{*}$, a memory whose content is (2), John's memory is true only if John has been elected prior to $t^{\star}$. On this view, both the pastness of the remembered event and the subject's involvement in that event derive from the fact that what is represented is represented in the memory mode. Again, we find that the truth-conditions are reflexive, but the self-reference bit comes from the mode. The content proper — what the subject remembers - is very simple, and it is not self-referential.

The second example is the state of relief, exemplified by Prior's utterance 'Thanks goodness that's over !' (Prior 1963). According to Higginbotham (1995), this is a complex state involving an emotion (relief) and, causing the emotion, a doxastic state (the belief that the painful episode is over). The content of the doxastic state refers to the complex state of which it is a part : the painful episode the termination of which brings relief must have been painful to the subject of the complex relief state, and it must be past with respect to that very state. The state is reflexive because its content involves a reference to the state itself.

Again, while I agree that the state is reflexive in some sense, I would offer a much simpler analysis. Following Prior, I would say that in 'Thanks goodness that's over', the sentence 'that's over' expresses a time-relative proposition, true at any time $t$ iff the painful episode is over at $t$. What brings relief is the subject's belief, at $t^{*}$, that this proposition holds. The subject's belief is indeed true iff the time-relative proposition in question is true at the time of the thought episode, that is, at $t^{\star}$; but this does not make $t^{\star}$ (or the thought episode) a constituent of the proposition that is the (narrow) content of the relief-causing belief. $t^{*}$ only comes into the picture through the act of asserting that proposition, linguistically or mentally. To assert the proposition is, in effect, to apply it to the current time.

This type of analysis has several advantages over the Searle-Higginbotham analysis. Among the reflexive states, many are shared with all sorts of animals (e.g. dogs) to which one does not want to ascribe the ability to entertain complex reflexive contents of the sort posited by the self-referential analysis. ${ }^{8}$ It is much more plausible

\footnotetext{
${ }^{7}$ Again, Searle would (rightly) add a causal condition : the remembered event must be the causal source of the current memory.

${ }^{8}$ I am indebted to Ned Block for emphasizing this point. Searle himself has responded to a similar worry expressed by Burge (1991), but I find his response puzzling. Searle says that
} 
to view the self-reference at issue as secured by the architecture of the system. Another advantage of my analysis is that it offers a simple solution to a vexing problem in the analysis of episodic memory. In the last section of this paper, I briefly present the problem and its solution.

\section{Time and memory}

Episodic memories are mental states which presuppose other mental states, namely perceptual experiences, to which they are related both causally (the memory derives from the perceptual experience, which leaves it as a 'trace') and semantically (the memory inherits the content of the perceptual experience). As Evans (1982) puts it, we need to be able to use information gathered through perception at a later time, and for that we need a mechanism for retaining information. Memory is that mechanism. Or rather, it is a family of mechanisms, corresponding to distinct ways of retaining information. In semantic memory, we retain the beliefs once formed on the basis of perception (or on any other basis - what is retained is only the output of the belief-fixation mechanism, so the etiology of the belief is irrelevant). In episodic memory, we retain the perceptual experiences themselves. I will be concerned only with the second type of memory, where a memory state is an experience similar to the perceptual experience from which it derives.

The crucial feature of episodic memories, besides their being experiential states, is that they share their content with the perceptual experiences from which they derive : they represent the same event or scene as the perceptual experience which is their ancestor. That is what episodic memory is for - it is supposed to replicate the perceptual experience. However, that is not all there is to say about

\footnotetext{
what he presents as the self-referential content of the visual experience is not something which the subject of the experience (possibly a dog, or a small child) has to entertain or somehow represent. Searle says he only claims that 'the visual experience itself functions self-referentially in fixing its truth-conditions' (Searle 1991 : 228). But that is precisely my point : the self-reference results from the way perception works, but it is not a feature of the content of the subject's representations, in the narrow sense of content. If Searle is right that Burge's objection rests on a misunderstanding, then perhaps this chapter ought to be seen as a clarification of Searle's position rather than a critique.
} 
memory. Even though the function of memory is to replicate the perceptual experience and, in particular, to carry the same content as that of the perceptual experience, still there is a fundamental difference in content between memory and the perception on which it is based.

I see that there is a large tree standing in front of me. Later, I remember that there was a large tree standing in front of me. This way of putting things reveals the essential difference : perception and memory relate to the same scene or event, but in memory the scene or event is presented as past. I remember that there was a large tree standing in front of me.

There is an obvious tension between the two elements I have just mentioned. Does a memory state have the same content as the perceptual state from which it derives, or does it have a different content? The answer seems to be : both ! The scene or event the memory is about is clearly the same as the scene or event the initiating perception is about (that is what makes memory memory), but it not the same since perception represents a present event (and represents it as present) while memory represents a past event (and represents it as past).

Faced with this tension, the obvious move is to distinguish two components in the content of a memory. One component is common to the memory and the perception from which it derives. Since that component is shared, the memory 'has the same content as' the perception. But the content of the memory involves an additional element, which is responsible for the difference between the memory and the perceptual state. Thus William James defines memory as 'the knowledge of an event..., of which in the meantime we have not been thinking, with the additional consciousness that we have thought or experienced it before' (James $1890: 648$, cited in Hoerl 2001 : 326 ; my emphasis). Here the 'knowledge of the event' is what is common to the perceptual state and the memory state; the additional component is responsible for the 'feeling of pastness' which differentiates memory from perception.

On this view the content of memory is conjunctive. The first conjunct is what is shared with perception ; the second conjunct differentiates memory from perception. The first conjunct represents a scene or event in the world ; the second conjunct represents the subject's past perceptual experience of that scene or event - hence the second conjunct is meta-representational. This is very similar to Searle's analysis of the content of perceptual experiences. 
Attractive though it is, there is a serious problem with the conjunctive analysis. It takes the content of the memory experience to consist of the content of the perceptual experience together with an additional element. But in what sense does the content of the memory experience contain that of the perceptual experience ? In perceiving the flower, I judge that there is a flower there. In remembering the flower, I do not judge that there is a flower there - only that there was one. So it does not seem that one can get to the content of memory by simply adding something to the content of perception.

In response to this objection, we may revise the analysis and interpret differently the idea that the content of memory contains the content of perception as a proper part. We may give up the conjunctive analysis and consider the content of the perceptual experience as occurring in the content of the memory not as an independent conjunct, but as a subordinate, embedded part. Instead of ' $p$ and I once perceived that $p$ ' the content would be simply 'I once perceived that $p$ '. (To this, following Searle, we may add the further idea that the present memory state is caused by that earlier perception : 'I once perceived that $p$ and that perception is causally responsible for this memory experience'.) The content of the perception occurs here as mentioned in the metarepresentational component, which now exhausts the content of the memory instead of being only a part of it. This view I call the metarepresentational analysis. ${ }^{9}$

\footnotetext{
${ }^{9}$ For this analysis to get off the ground, a few adjustments are necessary. First, the paraphrase 'I once perceived that $p$ ' is misleading. It does not capture the experiential component of memory - the fact that in memory, the nonconceptual content of the perceptual experience is retained. A better paraphrase would be : 'I had perceptual experience XXX', where 'XXX' does not merely specify the conceptual content of the perceptual judgment, but, as it were, 'quotes' the perceptual experience directly. Another adjustment is needed to capture the epistemic value of memory, namely the fact that, if I remember that $p$, I am thereby justified in judging that it was the case that $p$. That would not be the case if the content of memory was simply a representation of a (possibly non veridical) past perceptual experience. For that reason, Jordi Fernandez has suggested adding the condition that the past perceptual experience which memory represents is represented as veridical (Fernandez forthcoming).
} 
This solution to the problem raises another problem, however. The metarepresentational theory presents memory as primarily about our perceptual experience, and only indirectly about the world. I share Evans's protest that

We no more have, in memory, information that is primarily about our past experiences than we have, in perception, information which is primarily about our present experiences. Just as perception must be regarded as a capacity for gaining information about the world, so memory must be regarded as a capacity for retaining information about the world. (Evans $1982: 240$ )

In this respect the conjunctive theory fares better than the metarepresentational theory. The conjunctive theory integrates a metarepresentational component (corresponding to the subject's consciousness of being in a state which causally derives from a previous perception), but it also incorporates the direct representation of a state of affairs in the world, and straightforwardly captures the idea that the memory state retains the content of the perceptual state.

The problem we have raised for the conjunctive theory was that memory does not preserve the content of perception but transforms it by putting it, as it were, in the past tense. That is why it does not seem that one can get to the content of memory by simply adding something to the content of perception. Adding is not enough ; one needs to subtract something as well - namely the present tense or, less metaphorically, the feeling of presentness which colors the perception of the scene. In shifting from perception to memory, this feeling is removed, and it is replaced by the feeling of pastness which colors the representation of the scene in memory.

In the framework I have sketched, this problem simply does not arise. As in the conjunctive analysis, there are two components, one of which represents a state of affairs in the world. But in my framework that component is temporally neutral - it is a time-relative proposition which does not, by itself, specify a time - so there is no objection to saying that it is common to perception and to the resulting memory.

The complete content of a perceptual state is analysed into (i) a content in the narrow sense and (ii) a situation with respect to which that content is supposed to be evaluated. The complete content is distributed, and that means that what the situation component supplies need not be replicated in the content proper. Now the content of a perceptual experience is relative to the situation of perception (i.e. the 
situation which affects the subject's senses and is causally responsible for the perceptual state). This relativity extends to time : the content of perception is temporally neutral, but it is evaluated with respect to the time of the perceptual experience. So the subject has, at $t$, a perceptual experience the content of which is the time-relative proposition that there is a flower there, and that proposition is presented as true at $t$, the time of the present perceptual experience.

Since the content of the perception, in the narrow sense, is temporally neutral, there is no objection to saying that it is preserved in memory. In memory, the same time-relative proposition that there is a flower there is presented as true with respect to the situation (and the time) of the earlier perceptual experience rather than the situation (and the time) of the present memory experience. In the analysis of memory just as in the analysis of perception, the temporal element is carried by the situation of evaluation. ${ }^{10}$

\footnotetext{
${ }^{10}$ At this point the metarepresentational theorist can make the same inadequate response which, in section 3, I said Searle could make. It runs as follows : the feeling of pastness, just like the feeling of presentness that accompanies perception, is an aspect of the content of memory. There is a clear phenomenological difference between memory and perception, having to do with their respective temporal orientations. This cannot be expelled out of the content, however narrow we construe that notion of content. So, for example, Mike Martin writes:
}

The mere possibility that recall and experience might coincide in content raise[s] the worry that the phenomenology of recall might then have to be identified with that of sensory experience. (Martin $2001: 278$; emphasis mine)

But there is absolutely no reason to consider that phenomenology supervenes on content in the narrow sense. The mode contributes to the phenomenology, since the mode is something the subject is aware of. In the memory mode, the content is presented as true with respect to a past perceptual situation, hence the scene represented is felt as past. In the perception mode, the content is presented as true with respect to the current perceptual situation, hence the scene represented is felt as present. This introduces a difference in the complete content of the respective states, a difference which the phenomenology reflects. 


\section{References}

Bach, Kent (this volume). Searle against the World : How can Experiences Find their Objects ?

Barwise, Jon and John Perry (1983). Situations and Attitudes. Cambridge, Mass: MIT Press/Bradford Books.

Burge, Tyler (1991). Vision and Intentional Content. In E. Lepore and R. Van Gulick (eds.), John Searle and His Critics, Oxford : Blackwell, pp. 195-213.

Evans, Gareth (1982). The Varieties of Reference, ed. J. McDowell, Oxford:

Clarendon Press.

Fernandez, Jordi (forthcoming). The Intentionality of Memory. Australasian Journal of Philosophy.

Higginbotham, James (1995). Tensed Thoughts. Mind and Language 10 : 226-249. Higginbotham, James (2003). Remembering, Imagining, and the First Person. In A. Barber (ed.), Epistemology of Language, Oxford : Oxford University Press, pp. 496533.

Hoerl, Christoph (2001). The Phenomenology of Episodic Recall. In C. Hoerl and T. McCormack (eds.), Time and Memory, Oxford : Oxford University Press, pp. 315335.

James, William (1890). Principles of Psychology, vol. 1. London : Macmillan. Martin, Michael (2001). Out of the Past : Episodic Recall as Retained Acquaintance. In C. Hoerl and T. McCormack (eds.), Time and Memory, Oxford : Oxford University Press, pp. 257-284.

Prior, Arthur (1963). Thanks Goodness That's Over. Reprinted in his Papers in Logic and Ethics, London: Duckworth, 1976, p. 78-84.

Prior, Arthur (1967). Past, Present and Future. Oxford : Clarendon Press. Prior, Arthur (1968). Papers on Time and Tense. Oxford : Clarendon Press. Prior, Arthur (1977), with K. Fine. Worlds, Times and Selves. London : Duckworth. Recanati, François (1981). Les Enoncés performatifs. Paris : Editions de Minuit. Recanati, François (1987). Meaning and Force. Cambridge : Cambridge University Press.

Recanati, François (1996). Domains of Discourse. Linguistics and Philosophy 19 : 445-75. 
Recanati, François (1997). The Dynamics of Situations. European Review of Philosophy 2: 41-75

Recanati, François (1999). Situations and the Structure of Content. In K. Murasugi and R. Stainton (eds.), Philosophy and Linguistics, Westview, Boulder, Colorado, pp. 113-165.

Recanati, François (2000). Oratio Obliqua, Oratio Recta. An Essay on Metarepresentation. Cambridge, Mass : MIT Press/Bradford Book. Recanati, François (forthcoming). Perspectival Thought : A Plea for (Moderate) Relativism.

Searle, John (1969). Speech Acts. Cambridge: Cambridge University Press.

Searle, John (1983). Intentionality. Cambridge: Cambridge University Press.

Searle, John (1991). Reference and Intentionality. In E. Lepore and R. Van Gulick (eds.), John Searle and His Critics, Oxford : Blackwell, pp. 227-241.

Sperber, Dan (1982). Comments on Clark and Carlson's Paper. In N. Smith (ed.), Mutual Knowledge, London : Academic Press, pp. 46-51. 